\title{
IDENTIFICATION AND DESCRIPTION OF BUCEPHALUS MINIMUS (DIGENEA: BUCEPHALIDAE) LIFE CYCLE IN PORTUGAL: MORPHOLOGICAL, HISTOPATHOLOGICAL, AND MOLECULAR DATA
}

\author{
Susana Pina, Teresa Barandela, Maria João Santos`, Fernanda Russell-Pinto†, and Pedro Rodriguesł \\ Laboratory of Aquatic Zoology, ICBAS - Abel Salazar Institute for the Biomedical Sciences, University of Porto, Largo Prof. Abel Salazar, 2, \\ 4099-003, Porto, Portugal. e-mail: smpina@icbas.up.pt
}

\begin{abstract}
The cercaria of Bucephalus minimus infects the digestive gland and gonads of its first intermediate host, the edible cockle, Cerastoderma edule. Light microscopy (LM) and scanning electron microscopy (SEM) of the cercaria showed a tail formed by a central stem, with 2 long contractile arms presenting distinct morphological surfaces. The encysted metacercaria naturally infected the flathead grey mullet, Mugil cephalus. The cysts found in the heart, liver, and spleen were shown to be identical by the internal transcribed spacer (ITS1) sequence and morphological features and were associated with encapsulation, recruitment of cell infiltrates, and presence of melanomacrophages and adipose tissue. To establish the life cycle, we compared the ITS1 sequence in an adult from the known definitive host, Dicentrarchus labrax; encysted metacercariae from the liver, heart, and spleen of M. cephalus; and a cercaria from C. edule. With this comparison, we determined that they had a $100 \%$ similarity. Therefore, the ITS1 sequence data clearly indicate that these 3 parasitic stages belong to the same species, i.e., B. minimus.
\end{abstract}

The Bucephalidae Poche, 1907, are digenetic trematodes found in the intestine of marine, brackish water, and freshwater fish. They differ from all other digeneans by the configuration of their digestive system and terminal genitalia and by the presence of an anterior rhynchus, for attachment, that is dissociated from the digestive system (Overstreet and Curran, 2002; Bott and Cribb, 2005). Although the taxonomy of the genus $\mathrm{Bu}$ cephalus Baer, 1827 has been debated for many years, it was recently recognized that the previous designations, i.e., Gasterostomum minimum Stossich, 1887, Dolichoenterum lamirandi Carrère, 1937, Bucephalopsis minima (Stossich 1887), Labratrema lamirandi (Carrère 1937), and Labratrema minimus (Stossich 1887), were considered as synonyms of Bucephalus minimus (Stossich 1887) (Overstreet and Curran, 2002; Bartoli et al., 2006), a designation that was used in this study.

The B. minimus life cycle has been the object of several studies from which a number of different intermediate hosts have been reported. The life cycle starts with the infection of Cerastoderma edule (Malek, 2001; Baudrimont and de Montaudouin, 2007) or Cerastoderma glaucum (Maillard, 1975, 1976), which are bivalves known to be first intermediate hosts for the sporocysts and cercariae life stages. Cercariae emerge from the host and invade several fish species, such as Pomatoschistus microps (Maillard, 1975, 1976; Faliex and Morand, 1994; Malek, 2001), Pomatoschistus minutus (Faliex and Morand, 1994; Malek, 2001), Pomatoschistus minimus (Faliex and Morand, 1994; Baudrimont and de Montaudouin, 2007), Atherina boyeri (Faliex, 1991; Faliex and Morand, 1994), Liza ramada (Maillard, 1975; Faliex, 1991; Faliex and Morand, 1994), and Sparus aurata (Faliex and Morand, 1994), which act as a second intermediate hosts for metacercariae. All authors are in agreement that the life cycle is complete when the definitive host, Dicentrarchus labrax, is infected by consuming the sec-

Received 28 May 2008; revised 27 June 2008; accepted 8 August 2008.

* Department of Zoology-Anthropology, Faculty of Sciences, University of Porto, Praça Gomes Teixeira, 4099-002, Porto, Portugal.

$\dagger$ CIMAR-CIIMAR - Centre for Marine and Environmental Research, University of Porto, Rua dos Bragas, 289, 4050-123, Porto, Portugal.

$\ddagger$ Department of Iron Genes and Immune System, IBMC - Institute for Molecular and Cell Biology, Rua do Campo Alegre, 823, 4150-180, Porto, Portugal. ond intermediate host. Knowledge of the life cycle of bucephalid digeneans and the pathologies that they cause is very important, since these parasites infect molluscs and marine fish of great commercial value.

The infaunal bivalve, $C$. edule, and the flathead grey mullet, Mugil cephalus, are common species off the European Atlantic coast, including the northwest and south coasts of Portugal. Cerastoderma edule and $M$. cephalus are known to be hosts for the larval stages of several digeneans (Merella and Garippa, 2001; Russell-Pinto et al., 2006; Baudrimont and de Montaudouin, 2007). These species have considerable economic and social impact in Portugal, where they are extensively consumed by humans (Russell-Pinto, 1990; Muzavor et al., 1993).

Histological and morphological studies have focused on the bivalves (first intermediate hosts) (Cheng and Burton, 1965; Khamdan, 1998; da Silva et al., 2002; Laruelle et al., 2002). However, the pathology associated with the presence of metacercariae in fish (second intermediate hosts) has received less attention. The metacercariae cysts develop in various internal organs and in the muscles of teleost fish in considerable numbers, causing internal damage, particularly in the liver, where the cysts may decrease organ size and function (Faliex, 1991; Faliex and Morand, 1994).

The identification of digenean parasites is essential to enable the study and clarification of their complex life cycle. This identification, as well as the establishment of a link between the different larval stages, is extremely difficult when only morphological characteristics are used. However, these problems may be overcome by employing molecular biology techniques. The nuclear ribosomal RNA genes, particularly the ITS, allow differentiation between closely related digeneans species and have been widely used to study the relationships between a number of parasitic flatworms (Blair et al., 1996; Bartoli et al., 2000).

The aim of the present study was to perform a detailed examination of the morphology of the different larval stages and the adult of B. minimus life cycle, using LM and SEM. In addition, positive identification of the cercaria and metacercaria larval stages and the adult of this species was investigated. We also used the ITS1 sequence to establish an unequivocal correspondence between the 3 life cycle stages. Finally, we histologically analyzed the internal organs of $M$. cephalus to assess 
the extent of damage caused by the encysted metacercariae of B. minimus.

\section{MATERIALS AND METHODS}

\section{Collection and preparation of specimens}

Cerastoderma edule was collected at site 1 (Russell-Pinto, 1990), S. Jacinto Channel, Ria de Aveiro, Portugal $\left(40^{\circ} 30^{\prime} \mathrm{N}, 8^{\circ} 43^{\prime} \mathrm{W}\right)$. The study was conducted in April 1997 and from March through August 2004. In total, 1,415 specimens of $C$. edule were examined. The cockles were maintained alive in laboratory aquaria filled with aerated and filtered brackish water. Specimens were examined for sporocysts containing $B$. minimus cercariae. After removal, the sporocysts were subjected to a detailed LM and SEM study. Several cercariae released from the cockles were flattened under a cover slip, and their anatomy and morphology were studied and photographed.

For SEM, isolated cercariae were processed as described by RussellPinto and Bartoli (2002). Briefly, the cercariae were fixed in $2.5 \%$ glutaraldehyde buffered with $0.1 \mathrm{M}$ sodium cacodylate at $\mathrm{pH} 7.4$, for $2 \mathrm{hr}$ at $4 \mathrm{C}$. Fixed specimens were washed for an additional $2 \mathrm{hr}$ at $4 \mathrm{C}$ in the same buffer. They were post-fixed for $1-2 \mathrm{hr}$ in $1 \%$ osmium tetroxide in the same buffer, rinsed in $0.1 \mathrm{M}$ sodium cacodylate for $30 \mathrm{~min}$ at room temperature, and dehydrated. The samples were critical point dried in $\mathrm{CO}_{2}$. Mounted specimens were coated with gold and photomicrographs were obtained with a JEOL-JSM-6301 F (Tokyo, Japan) SEM operating at $15 \mathrm{KV}$.

Specimens of $M$. cephalus were captured from Douro River estuary in May 2003, transported alive to the laboratory, and stored in tanks filled with filtered and aerated salt water. Necropsies were carried out for 10 specimens and gross anatomy of 2 infected fishes was examined. After careful dissection, the liver, spleen, and heart were removed to search for encysted metacercariae and to study the histopathology caused by the presence of parasites. Some isolated cysts were photographed and frozen in $50 \mu \mathrm{l}$ of distilled water at $-20 \mathrm{C}$ for DNA analysis. In vitro metacercariae excystment was carried out according to Irwin et al. (1984). For LM, some metacercariae were processed according to Russell-Pinto et al. (2006).

Wild D. labrax specimens were obtained from the local market in April 2007. Eight fresh specimens were examined. After dissection, the intestine was removed to search for adult stages of $B$. minimus. The isolated adults were fixed in Berland's fluid and then stained with iron acetocarmine as described by Georgiev et al. (1986). Several adults were stored in ethanol for further DNA analysis. Voucher specimens have been deposited in The Natural History Museum, London, U.K., under accession no. 2008.7.15.4-15.

\section{Histological analysis}

For histological preparations, liver, spleen, and heart fragments were excised from the flathead grey mullets and immediately fixed in buffered $10 \%$ formaldehyde for $24 \mathrm{hr}$ at $4 \mathrm{C}$. After washing, samples were dehydrated through an ethanol series, treated with xylene, embedded in paraffin wax, and sectioned. The 5- $\mu \mathrm{m}$ sections were stained with hematoxylin-eosin (H\&E).

\section{Molecular analysis, DNA extraction, amplification, and sequencing}

DNA from 200 cercariae removed from C. edule; 15, 20, and 30 encysted metacercariae isolated from $M$. cephalus liver, heart, and spleen, respectively; and 2 adults found in naturally infected $D$. labrax was extracted using a Sigma (St. Louis, Missouri) kit (GenElute mammalian genomic DNA kit) following the manufacturer-recommended protocol, with the exception that complete digestion was extended to overnight at $55 \mathrm{C}$ instead of incubation at $70 \mathrm{C}$ for $10 \mathrm{~min}$ (Pina et al., 2007). Polymerase chain reaction (PCR) amplifications were performed in a total volume of $50 \mu \mathrm{l}\left(36.3 \mu \mathrm{l} \mathrm{H}_{2} \mathrm{O}, 5 \mu \mathrm{l} \mathrm{Taq}\right.$ buffer, $1 \mu \mathrm{dNTP}$, $1.5 \mu \mathrm{MgCl}_{2}, 0.5 \mu \mathrm{l}$ of each primer, $0.2 \mu \mathrm{l}$ platinum Taq polymerase, $5 \mu \mathrm{l}$ of template DNA solution), with the following thermocycling profile: 5 min denaturation at $94 \mathrm{C}$; 40 cycles for $30 \mathrm{sec}$ at $94 \mathrm{C}, 30 \mathrm{sec}$ at $54 \mathrm{C}, 2 \mathrm{~min}$ at $72 \mathrm{C}$, and a final extension for $10 \mathrm{~min}$ at $72 \mathrm{C}$. The ITS 1 region of the rDNA was amplified using a digenean-specific primer located 195 base pairs (bp) from the $3^{\prime}$ end of the $18 \mathrm{~S}$ rDNA (5'-
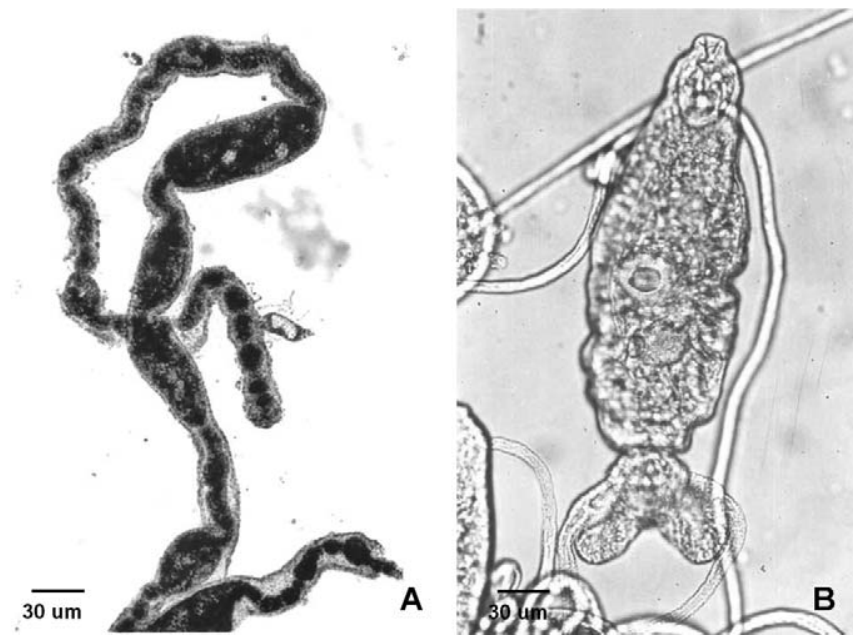

FIGURE 1. Photomicrographs of B. minimus life cycle stages. (A) Sporocyst from $C$. edule. (B) Light morphology of the cercaria.

GGT AAG TGC AAG TCA TAA GC-3'), and a universal primer located $35 \mathrm{bp}$ from the $5^{\prime}$ end of the $5.8 \mathrm{~S}$ rDNA $\left(5^{\prime}\right.$-GCT GCG CTC TTC ATC GAC A-3') (see Bartoli et al., 2000). PCR amplicons were excised from the gel and purified using Qiagen Qiaquick gel extraction kit (Valencia, California) and sequenced. Similar sequences were obtained from Basic Local Alignment Search Tool (BLAST), and were compared using the software Clustal W1.82w. Sequence data were submitted to GenBank under accession nos. DQ869532, EF644420, and EF644421.

\section{RESULTS}

\section{Diagnostic characters of Bucephalus minimus (Stossich 1887) (Figs. 1-4)}

Sporocysts: Multi-branched with constrictions; yellowish in color and comprising a great number of cercariae at different stages of development (Fig. 1A). They were observed in the digestive gland and gonads of the cockle replacing, to a large extent, the respective tissues (data not shown). Prevalence in April 1997 was 2.03\% and, between March and August 2004, was $1.50 \%$.

Cercariae: Gasterostome type (Fig. 1B); slightly dorsoventraly flattened, showing a great size $(356 \mu \mathrm{m}$ length, $105 \mu \mathrm{m}$ wide) when distended. Conical cephalic region with a glandular organ, i.e., a rhynchus or haptor. Body enlarged at the posterior end. Forked tail with very extensive lateral arms, up to 5 times as long as the cercariae body length. Mouth opening at the middle of the ventral face.

As observed with SEM, the body is cylindrical, with a conical cephalic region (Fig. 2A) and a cephalic organ composed of a large number of evaginated glandular cells, which emerge through a triangular aperture (Fig. 2B). The tegument is uniformly pearled (Fig. 2C), with the exception of the ventral face, where minute pointed spines are present (Fig. 2D). Uniciliated sensory papillae are scattered along the dorsal and ventral face of the body. The mouth is surrounded by a strong sphincter, opening at the middle of the ventral face (Fig. 2E). Constriction differentiates the body of the cercariae from the tail. The tail is formed by a central stem and 2 long and extremely contractile arms of the furca (Fig. 2F). The furcae have 2 distinct morphological surfaces at the ventral face; one corresponds to a mus- 


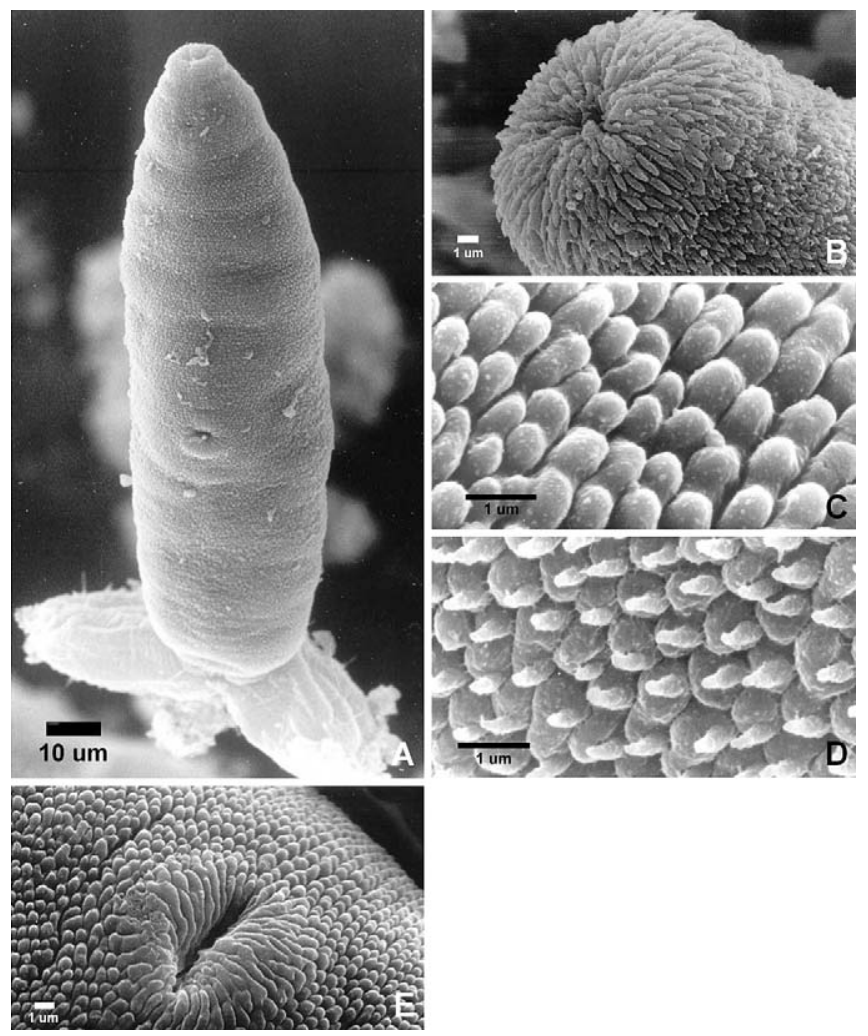

Figure 2. SEMs of B. minimus cercariae. (A) Ventral view of the cercaria; the cephalic organ was invaginated. (B) Cephalic organ morphology. (C) Pearled tegument of other regions of the body. (D) Spined tegument of anterior ventral region. (E) Oral sucker. (F) Furca and central stem where the adhesive organ is seen. (G) Segment of the ventral face arm structure where glandular and adhesive cells layers are observed. (H) Magnification of the central stem where the glandular secretions were observed.

cular cell row and the other to a secretory adhesive cell layer (Fig. 2G). Glandular cells are grouped at the base of the stem, where their secretions can be observed (Fig. $2 \mathrm{H}$ ) on the tegument surface; some unicialiated sensory papillae were present.

Metacercariae: The body is nearly spherical (Figs. 3A-C). The anterior edge of the cephalic organ is divided into 7 cordiform lobes, encircling the apical concavity (Fig. 3D). The digestive ceca include numerous refringent lipidic drops. The excretory vesicle is very large, filled with fine granules (Fig. 3A, 3B). Sketches show that genital organs such as the testes, ovary, and copulatory organ, occupy the same position as in the adults (Fig. 3C).

Adult: The adults are rounded and pyriform in shape. A bulky rhynchus has 7 cordiform and invaginable tentacles when fully protruded (Fig. 4A). The mouth is near the mid-body and is surrounded by a muscular pharynx. The ceca are sac-like, small, and in the body axis. Two testes are spherical, tandem or oblique, and postequatorial, one on the dorsal and the other on the ventral face (Fig. 4A). The cirrus pouch is cylindrical, mostly posttesticular, and contains an anterior seminal vesicle and a pars prostatica bordering the slightly winding ejaculator duct (Figs. 4B, 4C). The cirrus is in the form of a crooked lobe, projecting into the genital atrium. The genital pore is posterior and subterminal. The ovary is spherical, pretesticular, and on
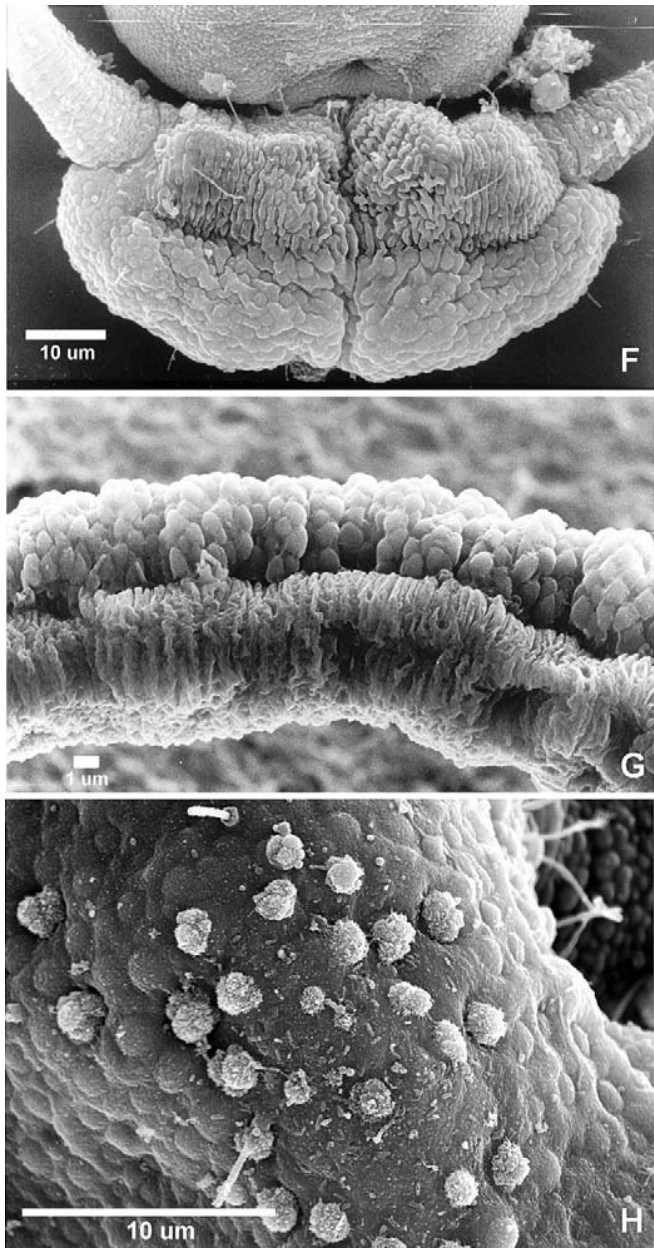

Figure 2. Continued.

the right side of the body. The vitellaria are divided into 2 distinct groups of 12-17 follicles each, slightly behind the testes (Fig. 4A, 4B). The uterus is strongly winding, with numerous small, yellowish, and operculate eggs (Figs. 4A-C). The excretory vesicle has thin walls between the digestive caecum, testes, and ovary; it is ventrally compressed by the cirrus pouch, with terminal opening defined by a strong sphincter. The adult of $B$. minimus was not firmly fixed to the wall of the digestive tract of its host; rather, it was free in the lumen of the middle segment of the intestine. Measurements are given in Table I.

\section{Taxonomic summary}

Hosts: Cerastoderma edule (Linnaeus, 1758) is the first intermediate host; $M$. cephalus (Linnaeus, 1758), the second intermediate host; and D. labrax (Linnaeus, 1758), the definitive host.

Sites of infection: The digestive gland and gonads are sites of infection for the sporocysts and cercariae in the cockle, with the heart, liver, and spleen for the encysted metacercariae, and the lumen of the middle segment of the intestine for the adult.

Locality: Collections for C. edule were made in the S. Jacinto Channel, Aveiro estuary, Portugal; the Douro River estuary, Portugal, for M. cephalus, and the northwest Atlantic coast of Portugal for D. labrax. 

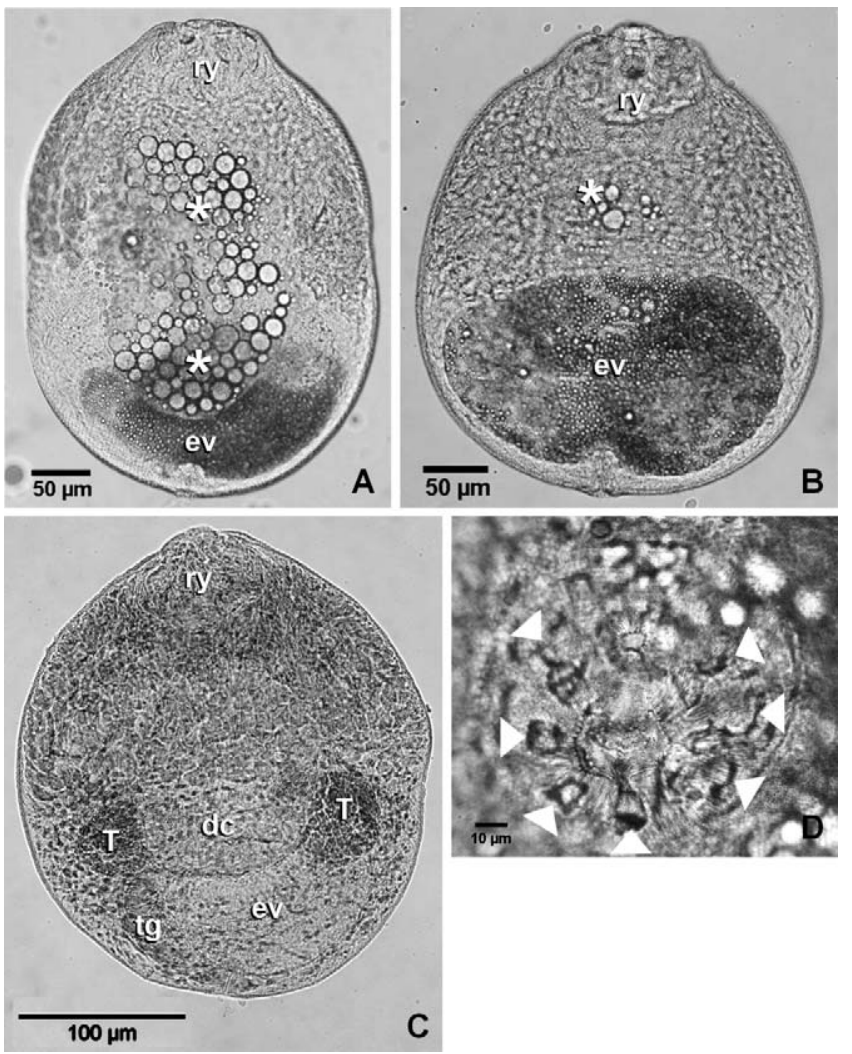

FIGURE 3. Photomicrographs of B. minimus excysted metacercariae isolated from the liver of M. cephalus. (A) (B) Light morphology of the metacercaria, in which lipidic drops that full the digestive caecum are evident (*); (A) younger and (B) older worm. (C) Light micrograph of a stained metacercaria. (D) High magnification of the cephalic organ-rynchus-with 7 cordiform lobes surrounding de apical concavity (arrowheads). dc, digestive caecum; ev, excretory vesicle; ry, rynchus; $\mathrm{T}$, testes; tg, terminal genitalia.

Prevalence: In April 1997, the prevalence was $2.03 \%$ and, from March to August 2004, it was $1.50 \%$ for sporocysts containing cercariae, $20 \%$ for metacercariae, and $25 \%$ for the adult form.

\section{Gross anatomy and morphological analysis of the Mugil cephalus organs}

With macroscopic examination of the heart, liver, and spleen, gross abnormalities of the morphology, color, and structure of these organs were evident. The heart presented numerous large, white spherical compact structures of different sizes, which were visible on the outside. The presence of these structures caused the loss of the usual smooth surface and bright red color of the pericardium. In the liver, a large number of small cysts was observed, homogeneous in size, embedded in the hepatic tissue without protruding to the capsular surface. A change in color from the usual brown to a pale greenish brown was observed. The spleen showed numerous large, white spherical structures, not compact, causing changes in the usual deep red color of this organ, turning it to a whitish shade.

In situ microscopic observations of the hepatic cysts revealed a spherical structure. The cysts had a thick wall, comprising 3 layers (Fig. 5A). The cyst wall of the metacercaria presented
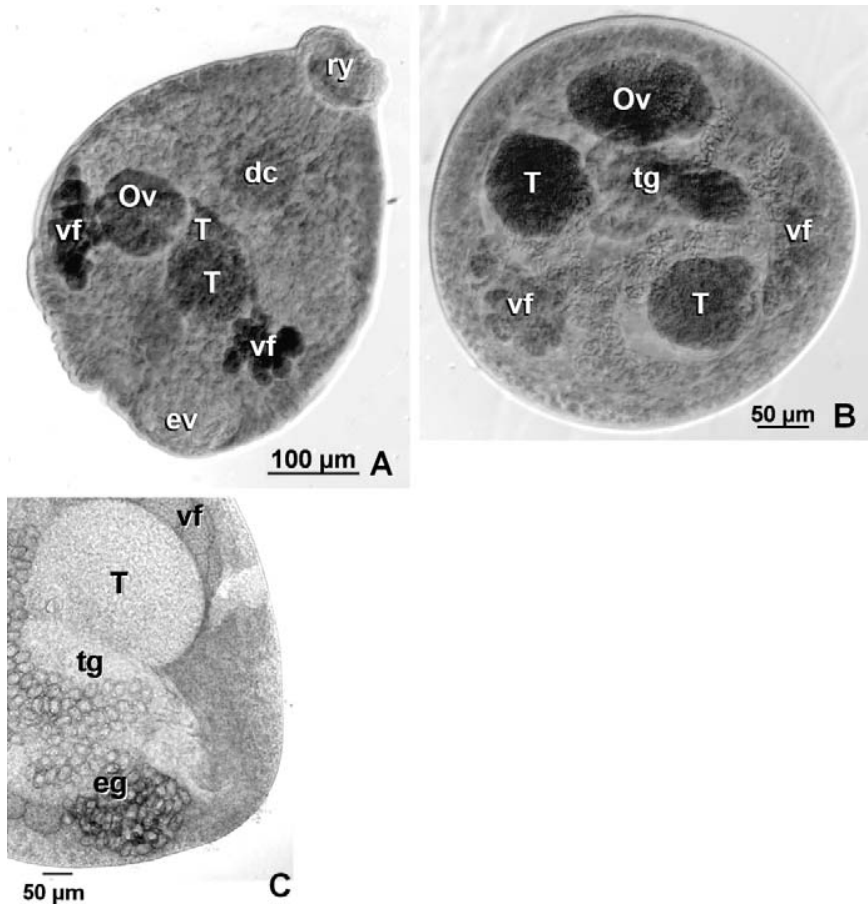

FIGURE 4. Photomicrographs of the adult of $B$. minimus isolated from D. labrax. (A) Differential interference contrast morphology of the adult in ventral view and (B) distal view. (C) High magnification of the posterior ventral region in light microscopy. dc, digestive caecum; eg, eggs; ev, excretory vesicle; Ov, ovary; ry, rynchus; T, testes; tg, terminal genitalia; vf, vitteline follicles.

an inner layer, limiting the cavity surrounding the worm. Adjacent to this, a middle layer could be seen, and outside of this, an outer layer was observed. These 2 external cyst walls formed a capsular coat.

\section{Histological analysis of the Mugil cephalus organs (Fig. 5)}

With histological analysis, it was possible to confirm the presence of cysts in all analyzed tissues. In the heart, we observed a large number of cysts (mean diameter, $154 \mu \mathrm{m}$ ) disseminated through the cardiac tissue (Fig. 5B). Some of the parasite cysts did not show a conspicuous capsule, although others were surrounded by a considerable number of fibrous tissue layers, forming a thick capsule (Fig. 5B). These compact structures did not always occur in a regular round shape, and cell infiltrates often were observed adjacent to the outer layer (Fig. 5C). In the liver, small cysts (mean diameter, $144 \mu \mathrm{m}$ ) without a fibrous capsule, homogeneous in size and shape, were observed (Fig. 5D). The cysts appear in the hepatic parenchyma and are frequently associated with melanomacrophage centers (Fig. 5D). Brown pigmented macrophages were often observed inside the hepatic metacercariae cysts (Fig. 5E). In the spleen, the parasite cysts (mean diameter, $147 \mu \mathrm{m}$ ) were surrounded by numerous splenic melanomacrophages and abundant adipose tissue (Fig. 5F).

\section{Molecular data}

The sequence of the amplified ITS1 fragment showed a single product, $787 \mathrm{bp}$ long. From the sequence analysis, the first 
TABLE I. Morphological measurements of adult stage of Bucephalus minimus.*

\begin{tabular}{lcclc}
\hline & & Mean \pm SD $\dagger$ & Range & $\mathrm{n}$ \\
\hline Body & length & $541.5 \pm 198.5$ & $366-1,088$ & 15 \\
& width & $364.7 \pm 94.4$ & $255-560$ & 15 \\
Rynchus & length & $81.7 \pm 13.9$ & $65-110$ & 15 \\
& width & $116.8 \pm 26.1$ & $88-180$ & 15 \\
Pharynx & length & $43.6 \pm 12.1$ & $25-68$ & 14 \\
& width & $46.5 \pm 13.0$ & $25-66$ & 14 \\
Testis dorsal & length & $112.9 \pm 33.0$ & $66-208$ & 15 \\
& width & $97.5 \pm 26.0$ & $48-158$ & 15 \\
Testis ventral & length & $110.6 \pm 32.8$ & $68-205$ & 15 \\
& width & $102.7 \pm 24.9$ & $68-170$ & 15 \\
Cirrus pouch & length & $177.3 \pm 49.4$ & $99-290$ & 15 \\
& width & $44.9 \pm 10.1$ & $33-63$ & 15 \\
Ovary & length & $97.3 \pm 18.6$ & $75-140$ & 15 \\
& width & $87.7 \pm 16.8$ & $66-130$ & 15 \\
Eggs & length & $22.1 \pm 1.4$ & $18-24$ & 104 \\
& width & $13.9 \pm 1.2$ & $10-15$ & 104 \\
\hline
\end{tabular}

* Measurements are in $\mu \mathrm{m}$.

$\dagger$ Standard deviation.

189 bases were identified as corresponding to the DNA coding for the ribosomal $18 \mathrm{~S}$ unit. The following 571 bases were the ITS1 sequence and the last 27 coded for the ribosomal 5.8.S unit. No identical sequence was found in GenBank. However, the ITS1 sequence obtained from this study presented a $91 \%$ similarity to the available ITS1 sequence known from Bucephalus polymorphus. The sequence encoding for the ITS1 region of the B. minimus cercariae, collected in naturally infected $C$. edule, was identical to the sequence obtained from the encysted metacercariae isolated from the liver, heart, and spleen of $M$. cephalus and to the sequence obtained from the adults isolated from naturally infected $D$. labrax.

\section{DISCUSSION}

The sporocysts of $B$. minimus parasitized the Atlantic cockle $C$. edule from Aveiro estuary, on the northwestern coast of Portugal. The finding of B. minimus in this particular geographical site reinforces the idea that the coast of Portugal may constitute an intermediate location for parasite species found in hosts from both the Atlantic and Mediterranean coasts (here, parasitizing C. glaucum) as pointed out earlier (Maillard, 1975, 1976; Faliex and Biagianti, 1987; Fares and Maillard, 1990; Saadfares and Combes, 1992; Faliex and Morand, 1994; ElDarsh and Whitfield, 1999; de Montaudouin et al., 2000; Sasal et al., 2000; Malek, 2001; Desclaux et al., 2002; Russell-Pinto et al., 2006).

Previous studies revealed that the presence of sporocysts of $B$. minimus in $C$. edule affects the host tissues, namely, the digestive gland and gonads. The high number of sporocysts invading the host organs is known to induce castration of the gonadal tissue (James, 1969; Khamdan, 1998) and affect the normal function of the digestive gland (Shelley et al., 1988; Desclaux et al., 2002).

The absence of significant spines on the tegument of cercariae, except for the minute spines on the ventral face, suggests that these cercariae do not need spines to disrupt the sporocyst wall and to penetrate the second intermediate host. This event
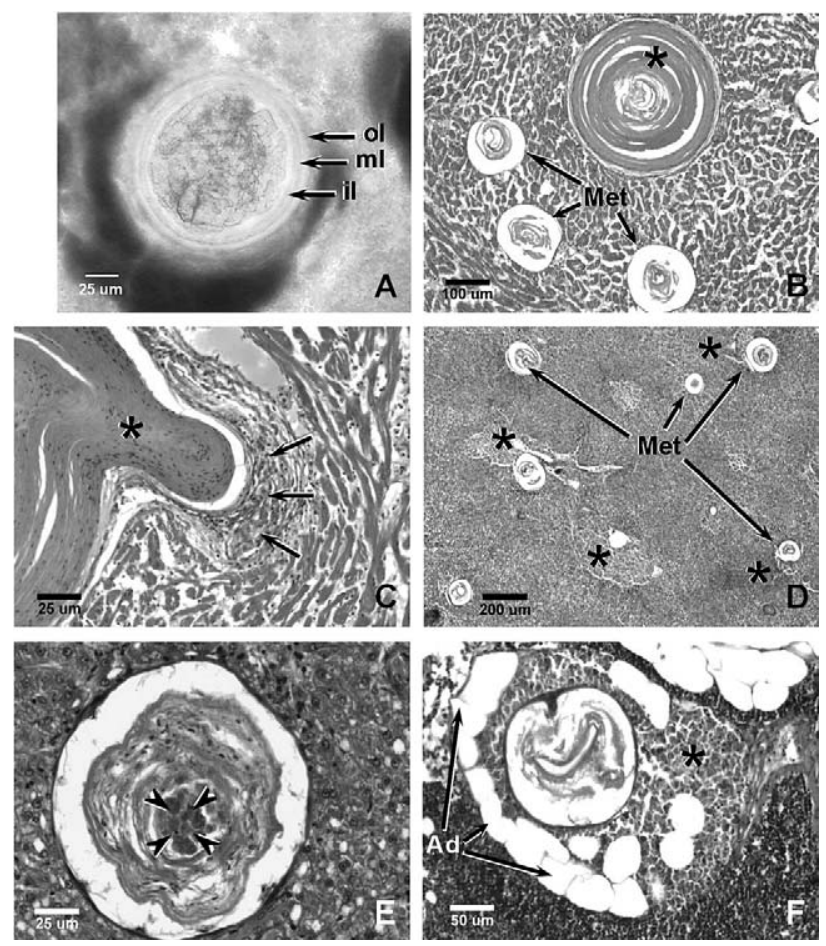

FIGURE 5. Mugil cephalus naturally infected by B. minimus metacercariae. (A) Light micrograph of metacercarial cyst removed from $M$. cephalus liver. (B-F) Light micrographs of different tissue paraffin sections of $M$. cephalus stained with H\&E. (B) Cardiac tissue with encysted metacercariae, some of which are surrounded by a fibrous capsule $(*)$. (C) High magnification of the cyst fibrous capsule (*) with cellular infiltrate, in the cardiac parenchyma, adjacent to the metacercaria (arrows). (D) Liver with metacercariae at various developmental stages and melanomacrophages centers (*). (E) Hepatic metacercarial cyst with pigmented macrophages inside (arrowheads). (F) Spleen metacercarial cyst surrounded by adipocytes and melanomacrophage center (*). Ad, adipocytes; il, inner layer; Met, metacercariae; ml, middle layer; ol, outer layer.

is probably facilitated by the action of the glandular cells of the cephalic organ, the rhynchus. The long arms of the forked tail, with their conspicuous mass of adhesive cells, facilitate attachment of the worm to the second intermediate host tissues, a function many times attributed to the tegument spines (Scholz et al., 1992). The papillary surface morphology of the tegument of $B$. minimus results in an increase in the body surface area, which allows better absorption of nutrients (Dunn et al., 1987).

The excysted metacercariae exhibited several interesting characteristics. According to Maillard (1975, 1976), the digestive caecum was full of lipid droplets that result from the degradation of hepatic and sanguineous cells by digestion. The more that a metacercaria aged, the more the ceca retracted and emptied its contents. In contrast, the excretory vesicle became extended and filled with fine granules. Thus, it was possible to estimate age by simple examination of the digestive ceca and excretory vesicle.

The encysted metacercariae were observed in the heart, spleen, and liver of $M$. cephalus. The host reactions to the parasite varied according to the infected tissue. Overall, given the level of infection observed and the extension of tissue lesions registered, the organs' functions are expected to be seriously compromised. 
In the heart, cysts of different sizes were frequently observed surrounded by a strong fibrous capsule, often with the presence of mononuclear cells. This suggests an inflammatory-like reaction with recruitment of circulating mononuclear cells and fibroblasts from the surrounding cardiac tissue. The diversity in size of the cysts may indicate different stages of infection.

In the liver, the metacercariae cysts had a thick wall comprising 3 layers. As previously reported (Faliex, 1990, 1991), the inner layer probably derives from the parasite and the middle and outer layers derive from the host. These 2 layers sequester the parasite against a possible inflammatory reaction of the host (Faliex, 1990). In the present study, the hepatic cysts were frequently observed in the vicinity of melanomacrophages, suggesting an active tissue reaction against the parasite. Moreover, it was possible to observe melanomacrophages within the metacercariae cysts, in direct contact with the parasite.

In the spleen, the parasites were surrounded by melanomacrophages and adipose tissue. The spleens of teleost fish have melanomacrophage centers, known to be involved in the killing of microorganisms by different processes, but primarily by generation of oxygen-reactive species (Agius and Roberts, 2003). Thus, the involvement of the parasite by the splenic melanomacrophages may constitute a host response to the parasitic infection. The underlying cause for the presence of adipose tissue within the melanomacrophages centers is not clear; however, it is possible that this observation may be linked to the known generation of oxygen-reactive species by macrophages.

The degeneration of metacercariae observed in all infected organs can be related to the action of the host cells against the parasite (Faliex, 1990). In the present study, the dense metacercariae infection observed in flathead grey mullet organs does not seem to affect surrounding tissues. Occasionally, a severe infection can lead to the replacement of normal tissue by a compact mass of encysted metacercariae, leading to the death of the host (Maillard, 1976) and consequent economic losses given its commercial value.

The specific characters observed for adult $B$. minimus include the rounded body shape, the presence of a sucker-like rynchus that is topped by a ring of 7 retractable tentacles, gonads situated behind, but at the same level of the digestive ceca, and localization of the adult in the host. These observations are in agreement with descriptions of the adult stage by Yamaguti (1958), Maillard (1976), and Overstreet and Curran (2002). A direct comparison between the measurements presented in Table I and the morphometric data described by Maillard (1975) is difficult, due to the use of different fixation techniques. The level of prevalence observed for B. minimus (25\%), even with the limitation of the number of sea bass surveyed in this study, taken together with findings reported by Santos (1998), where a prevalence of $38 \%$ at the Aveiro estuary was registered, indicates that this species is common along the northern Portugal coast line.

Molecular methods based on DNA sequencing offer a new tool for larval stage identification (Jousson et al., 1998) and clarification of digenean life cycles (Bartoli et al., 2000; Jousson and Bartoli, 2000), overcoming the limitations of the morphological approach. In the present study, the ITS1 sequence of ribosomal DNA was used to identify the cercaria, metacercaria, and adult $B$. minimus, in order to clarify its life cycle. With this molecular method, it was possible to establish an un- equivocal link between $B$. minimus cercariae; the isolated cysts from liver, heart, and spleen of M. cephalus; and the adults collected from the middle intestine of D. labrax. The fact that the encysted metacercaria of B. minimus was found in $M$. cephalus is not surprising, since the flathead grey mullet is known to be a second intermediate host for a number of digenean parasites (Merella and Garippa, 2001). The high similarity (91\%) found between the ITS1 sequence of $B$. minimus presented in this study and the partial ITS1 sequence of $B$. polymorphus available in GenBank is expected, since both digenean parasites belong to the Buchephalidae and to Bucephalus.

\section{ACKNOWLEDGMENTS}

We thank the Cell Biology Laboratory at ICBAS, in particular Prof. Alexandre Lobo-da-Cunha, for use of the molecular biology equipment; João Villares Neves at IBMC, Porto University, for helping with the molecular biology techniques; Jessica Tajdari for technical assistance; and the anonymous referees who provided valuable comments on the manuscript.

\section{LITERATURE CITED}

Agius, C., AND R. J. Roberts. 2003. Melano-macrophage centres and their role in fish pathology. Journal of Fish Diseases 26: 499-509.

Bartoli, P., R. A. Bray, D. I. Gibson. 2006. Four closely related but forgotten species of Rhipidocotyle Diesing, 1858 (Digenea: Bucephalidae) in fishes from European seas. Systematic Parasitology 65: 129-149.

, O. Jousson, And F. Russell-Pinto. 2000. The life cycle of Monorchis parvus (Digenea: Monorchiidae) demonstrated by developmental and molecular data. Journal of Parasitology 86: 479489.

Baudrimont, M., And X. DE Montaudouin. 2007. Evidence of an altered protective effect of metallothioneins after cadmium exposure in the digenean parasite-infected cockle (Cerastoderma edule). Parasitology 134: 237-245.

Blair, D., A. Campos, M. P. Cummings, and J. P. Laclette. 1996. Evolutionary biology of parasitic Platyhelminths: The role of molecular phylogenetics. Parasitology Today 12: 66-71.

BotT, N. J., AND T. H. CRIBB. 2005. Prosorhynchoides lamprelli n. sp. (Digenea: Bucephalidae) from the brassy trevally, Caranx papuensis (Teleostei: Carangidae), from off Lizard Island on the Great Barrier Reef, Australia. Zootaxa 1059: 33-38.

Cheng, T. C., And R. W. Burton. 1965. Relationships between $\mathrm{Bu}$ cephalus sp. and Crassostrea virginica: Histopathology and sites of infection. Chesapeake Science 6: 3-16.

Da Silva, P. M., A. R. M. Magalhães, and M. A. Barracco. 2002. Effects of Bucephalus sp. (Trematoda: Bucephalidae) on Perna perna mussels from a culture station in Ratones Grande Island, Brazil. Journal of Invertebrate Pathology 79: 154-162.

de Montaudouin, X., I. Kisielewsi, G. Bachelet, and C. Desclaux. 2000. A census of macroparasites in an intertidal bivalve community, Arcachon Bay, France. Oceanologica Acta 23: 453-468.

Desclaux, C., X. De Montaudouin, and G. BaChelet. 2002. Cockle emergence at the sediment surface: "Favourization" mechanism by digenean parasites? Diseases of Aquatic Organisms 52: 137-149.

Dunn, T. S., R. E. B. Hanna, AND W. A. NizAmi. 1987. Ultrastructural and cytochemical observation on the tegument of three species of paramphistomes (Platyhelminthes: Digenea) from the Indian water buffalo, Bubalus bubalis. International Journal for Parasitology 17: 1153-1161.

El-DARSh, H. E. M., AND P. J. WhitFIELD. 1999. Digenean metacercariae (Timoniella spp., Labratrema minimus and Cryptocotyle concava) from the flounder, Platichthys flesus, in tidal Thames. Journal of Helminthology 73: 106-113.

FALIEX, E. 1990. Experimental infection of juveniles grey mullet, Liza ramada, by metacercaria of Labratrema minimus (Digenea: Bucephalidae): Ultrastructural analysis of the host-parasite relationship. In Pathology in marine science, F. O. Perkins and T. C. Cheng (eds.). Academic Press, London, U.K., 299-303. 
1991. Ultrastructural study of the host-parasite interface after infect of 2 species of teleosts by Labratrema minimus metacercariae (Trematoda, Bucephalidae). Diseases of Aquatic Organisms 10: 93-101.

- AND S. Biagianti. 1987. Metacercarial infection of marine fish by Labratrema minimus (Digenea, Bucephalidae). Histo-cytological analysis of host-parasite relationship. Aquaculture 67: 229-232. , AND S. MORAND. 1994. Population-dynamics of the metacercarial stage of the Buchepalid Trematode, Labratrema minimus (Stossich, 1887) from Salses-Leucate Lagoon (France) during the cercarial shedding period. Journal of Helminthology 68: 35-40.

FAres, A. S., AND C. MAILlard. 1990. Digenetic trematodes of Lebanese coast fishes-The complexes Lepocreadium album (Stossich, 1890) and Lepocreadium pegorchis (Stossich, 1900) (Lepocreadiidae). Systematic Parasitology 17: 87-95.

Georgiev, B., V. Biserkov, AND T. Genov. 1986. In toto staining method for cestodes with iron acetocarmine. Helminthologia 23: 279281.

Irwin, S. W. B., G. McKerr, B. C. Judge, And I. Moran. 1984. Studies on metacercarial excystment in Himasthla leptosoma (Trematoda: Echinostomatidae) and newly emerged metacercariae. International Journal for Parasitology 14: 415-421.

JAMES, B. L. 1969. The Digenea of the intertidal prosobranch, Littorina saxatilis (Olivi). Zeitschrift Zoologische Systematik und Evolutionsforschung 7: 273-316.

Jousson, O., AND P. BARTOLi. 2000. The life cycle of Opecoeloides columbellae (Pagenstecher, 1863) n. comb. (Digenea, Opecoelidae): Evidence from molecules and morphology. International Journal for Parasitology 30: 747-760.

L. ZaninetTi, AND J. PAwlowski. 1998. Use of the ITS rDNA for elucidation of some lifecycles of Mesometridae (Trematoda, Digenea). International Journal for Parasitology 28: 1403-1411.

Khamdan, S. A. A. 1998. Occurrence of Bucephalus sp. trematode in the gonad of the pearl oyster, Pinctada radiata. Environment International 24: 117-120.

Laruelle, F., D. P. Molloy, and V. A. Roitman. 2002. Histological analysis of trematodes in Dreissena polymorpha: Their location, pathogenicity, and distinguishing morphological characteristics. Journal of Parasitology 88: 856-863.

MAILlaRD, C. 1975. Labratrema lamirandi (Carrère, 1937) (Trematoda, Bucephalidae) parasite de Dicentrarchus labrax (L., 1758). Création du genre Labratrema. Cycle évolutif. Bulletin du Museum National d'Histoire Naturelle, Paris (3e Série, Zoologie) 193: 69_ 79.

. 1976. Distomatoses de poisons en milieulagunaire. Ph.D. thesis. University of Sciences and Technology of Languedoc, Montpellier, France, 383 p.

MALEK, M. 2001. Effects of the digenean parasites Labratrema minimus and Cryptocotyle concavum on the growth parameters of Pomatoschistus microps and $P$. minutus from Southwest Wales. Parasitology Research 87: 349-355.

Merella, P., and G. Garippa. 2001. Metazoan parasites of grey mullets (Teleostea: Mugilidae) from the Mistras Lagoon (Sardinia, western Mediterranean). Scientia Marina 65: 201-206.

Muzavor, S., L. M. Arruda, And J. P. A. S. Andrade. 1993. Roteiro ecológico da Ria Formosa, II-Peixes. Algarve em Foco, Faro, Portugal, $167 \mathrm{p}$.

Overstreet, R. M., And S. S. Curran. 2002. Superfamily Bucephaloidea Poche, 1907. In Keys to the Trematoda, Vol. 1, D. I. Gibson, A. Jones, and R. A. Bray (eds.). CAB International Publishing and The Natural History Museum, London, U.K., p. 67-110.

PinA, S. M. R., F. Russell-PinTo, AND P. Rodrigues. 2007. Clarification of Cercaria sevillana (Digenea: Microphallidae) life cycle using morphological and molecular data. Journal of Parasitology 93: 318-322.

RUSSELL-PINTO, F. 1990. Differences in infestation intensity and prevalence of hinge and mantle margin Meiogymnophallus minutus metacercariae (Gymnophallidae) in Cerastoderma edule (Bivalvia) possible species co-existence in Ria de Aveiro. Journal of Parasitology 76: 653-659.

- AND P. BARTOLI. 2002. Cercaria sevillana $\mathrm{n}$. sp. a new cercaria (Digenea: Microphallidae) from Nassarius reticulatus (L.) (Mollusca: Prosobranchia) in Portugal. Systematic Parasitology 53: 175-182.

, J. F. GonçAlves, AND E. Bowers. 2006. Digenean larvae parasitizing Cerastoderma edule (Bivalvia) and Nassarius reticulatus (Gastropoda) from Ria de Aveiro, Portugal. Journal of Parasitology 92: 319-332.

SAADFARES, A., AND C. COMBES. 1992. Abundance host size relationship in a fish trematode community. Journal of Helminthology 66: 187192.

SAnTos, M. 1998. Parasitas do robalo (Dicentrarchus labrax L.) da Ria de Aveiro e sua dinâmica populacional. Ph.D. thesis. University of Porto, Faculty of Sciences, Porto, Portugal, 261 p.

Sasal, P., P. Durand, E. Faliex, and S. Morand. 2000. Experimental approach to the importance of parasitism in biological conservation. Marine Ecology Progress Series 198: 293-302.

Scholz, T., O. Ditrich, AND M. GibodA. 1992. Study on the surface morphology of the developmental stages of the liver fluke, Opis thorchis viverrini (Trematoda: Opisthochiirdae). Annales de Parasitologie Humaine et Comparée 67: 82-90.

Shelley, C. C., J. S. Glazebrook, E. Turak, L. Winsor, and G. R. W. Denton. 1988. Trematode (Digenea: Bucephalidae) infection in the burrowing clam Tridacna crocea from the Great Barrier Reef. Diseases of Aquatic Organisms 4: 143-147.

Yamaguti, S. 1958. Systema helminthum, Vol. I, The digenetic trematodes of vertebrates-Part I. Interscience Publishers Inc., New York, New York, 979 p. 